\title{
Comparison of the effect of educational methods on students' knowledge, attitude and behavior about hookah smoking
}

Maryam Shojaeifar ${ }^{1}$, Shamsodin Niknami ${ }^{2}$, Ali Mirbalochzahi ${ }^{3}$, Mohammad Khammarnia $^{4}$, Alireza Khorram ${ }^{5}$

${ }^{1}$ M.Sc. Student of Health Education, Department of Health Education, Tarbiat Modares University, Tehran, Iran

${ }^{2}$ Ph.D. of Health Education, Associate Professor, Department of Health Education, Faculty of Medical Sciences, Tarbiat Modares University, Tehran, Iran

${ }^{3}$ Instructor of Health Education, Faculty Member, Iranshahr University of Medical Sciences, Iranshahr, Iran

${ }^{4} \mathrm{Ph}$.D. of Health Care Management, Assistant Professor, Department of Public Health, Faculty of Health, Zahedan University of Medical Sciences, Zahedan, Iran

${ }^{5}$ M.Sc. Student of Epidemiology, Department of Epidemiology, Faculty of Health, Zahedan University of Medical Sciences, Zahedan, Iran

\section{Type of article: Original}

\begin{abstract}
Introduction: Smoking tobacco by hookah may seriously affect the health of smokers and those exposed to smoke. This study aimed to compare the effect of educational digital media versus pamphlets on the reduction of hookah use among male high school students in Zahedan, Iran.

Methods: A semi-experimental study was conducted on 200 male high school students of Zahedan using multistage random sampling for three months in 2014. The samples were divided into two groups - the test (educated using digital films) and the control (educated using pamphlets) groups, and measurement was performed before and after intervention. The data collection instrument was a 53-item questionnaire consisting of demographic, knowledge, attitude, behavior and self-efficacy questions. Its validity and reliability were confirmed. The results before and after the intervention were analyzed using SPSS version 18, Mann-Whitney U test, Pearson-product moment correlation coefficient and Chi square test as well as one directional variance analysis.

Results: There was no significant relation between demographic and basic variables before intervention ( $>0.05$ ); however, the mean scores of knowledge, attitude, self-efficacy, and hookah using preventive behavior were significantly different between the two groups after the intervention $(p<0.05)$. Moreover, there was a meaningful relation among the demographic characteristics including age and attitude- the previous educational year's GPA and self-efficacy; and there was a significant relation between father education and self-efficacy. Moreover, there was a significant relation between the main variables of the study, concerning the relation of knowledge and attitude- knowledge and self-efficacy, and attitude and self-efficacy.

Conclusion: Educational digital media is more efficient than the pamphlet in the reduction of hookah use among the students; and that the media may be applied to prevent of hookah use among students.

Keywords: Digital media, Education, Students, Hookah
\end{abstract}

\section{Introduction}

\subsection{Background and study logic}

The global epidemic of tobacco smoking already kills around 5-6 million people yearly $(1,2)$ and in the current century, it will kill more than one billion people (1). Cigarette smoking is the most studied form of tobacco use, but another form that is emerging worldwide is hookah smoking (2). Hookah (also known as hubble-bubble, shishapipe, nargile arghile, or ghalyan) is a water pipe used for tobacco use. Hookah smoking was a traditional form of tobacco use (3-5), particularly in the Eastern Mediterranean region (6). Currently, the African, the Eastern

\section{Corresponding author:}

Associate Professor Dr. Shamsodin Niknami, Department of Health Education, Faculty of Medical Sciences, Tarbiat Modares University, Tehran, Iran. Tel: +98.9124057083, Fax:+985433295715, Email: niknami6@yahoo.com Received: June 23, 2016, Accepted: October 16, 2016, Published: February 2017 iThenticate screening: September 15, 2016, English editing: December 17, 2016, Quality control: January 12, 2017 (C) 2017 The Authors. This is an open access article under the terms of the Creative Commons Attribution-NonCommercialNoDerivs License, which permits use and distribution in any medium, provided the original work is properly cited, the use is non-commercial and no modifications or adaptations are made. 
Mediterranean, and the South-East Asia regions have the highest rates of hookah smoking $(2,7)$ but, it is growing rapidly in Europe, North and South America, and specifically in the US (3). A study in Iran showed that the prevalence of hookah smoking was $17.3 \%$ (8). Moreover, in Zahedan, in the southeast of Iran, the incidence of hookah smoking was reported as $21 \%$ among high school students (9). The health effects of hookah use are similar to cigarette tobacco use. Hookah contains many harmful toxicants similar to cigarettes, such as nicotine, tar and carbon monoxide $(3,10,11)$. The health effects related with hookah use may include cardiovascular disease, cancer, decreased pulmonary function, low birth-weight, adverse reproductive outcomes, periodontal disease, and nicotine dependence $(12,13)$. However, the health effects of hookah use are less understood by its users $(14,15)$. Smoking tobacco by hookah may seriously affect the health of smokers and those exposed to smoke (10). Flavored tobacco used with the hookah has an extremely higher nicotine content than cigarettes. For example, the study showed that one hookah session is equal to the production of carcinogens derived from 1 to 50 cigarettes (12). There is an increasing public health concern relevant to the rapid growth in hookah use especially among students and youth (12). Recent studies have documented that hookah smoking prevalence among college students and youth has increased in North America, the United States, and Europe. Hookah smoking is spreading rapidly among high school and college students, adolescents, and youth with an emerging trend. Hookah smoking studies among high school and college students in various countries showed the lifetime prevalence of $20 \%$ to $69 \%$ in the eastern Mediterranean region, $9.8 \%$ in the United States, $56 \%$ in Jordan, $44.3 \%$ in Lebanon, and $19.7 \%$ in Brazil (15) that indicated an emerging and worrisome trend of hookah use. Among Iranian university students, the studies reported a nearly $42.5 \%$ lifetime prevalence rate of hookah use with $18.7 \%$ within 30 days. In the US, the National Youth Tobacco Survey in 2014 estimated the highest current prevalence (10.7\%) of hookah smoking among youth and also estimated that $12.5 \%$ of high school students had used two or more tobacco products during the past 30 days. Hookah smoking prevalence was higher among students who were current or former smokers and students with close friends who smoked hookah. Also, prevalence is higher among boys than girls, and increases with grade (16). The students in higher grades are more likely to use a hookah. According to the US study, hookah smoking prevalence was higher among high school students than middle school students. In one study that was conducted in Canada, the current use of hookah was $0.5 \%$ in seventh grade, $1.1 \%$ in eighth grade, $2.3 \%$ in ninth grade, $3.4 \%$ in tenth grade, $4.3 \%$ in eleventh grade, and $5 \%$ in twelfth grade. The McKelvey et al, study that was conducted among school children in Irbid, Jordan showed that boys were more likely to use a hookah if they had teachers or siblings who smoked and for girls, if they had smoker friends. The study among Lebanon students showed that current cigarette usage, parent and peer smoking, older age, decreased religiosity, exposure to recent hookah advertising, and increased pluralistic ignorance were potentially correlated with hookah use. The study among Iranian university students showed that lifetime hookah smoking was associated with male sex and age and the highest prevalence observed was in students whose close friends were hookah smokers. The prevalence of hookah use among students is spreading rapidly over recent years (17). Perceptions of public acceptability and wrongly believed factors might be related to the high prevalence of hookah use. The common perception is that this product causes less harm to one's health than cigarettes, by passing through the water, and is less dependence-producing than cigarettes. In many countries, a new trend on hookah smoking has been developed and it is becoming a popular way to spend time with friends, and is part of a new lifestyle. In one study in the U.S., more than half of the students $(52.1 \%)$ perceived that hookah smoking was less addictive than cigarettes and one-year hookah smoking was related with perceptions of less harm and addictiveness and high social acceptability and popularity. In another study that was conducted among the Iranian students, the most important perceived reason was enjoyment (55.8\%). Also, hookah use is not as widely prohibited and there are special café and shops for hookah smoking which might encourage people to use them in social situations. The media and commercial marketing with safety associated claims, may also be the cause of hookah smoking spreading across the world, because of positive behavioral expectancies. Hookah smoking should be included in tobacco products' control efforts. Lack of information about the health effects of hookah use is one of the most important factors for hookah smoking growth. Education to youth and students, about the health effects, can increase their knowledge about the harmful effects of hookah use and change mistaken beliefs about this product in order to reduce hookah use prevalence among them.

\subsection{Objectives}

The purpose of this study was to determine the effects of two types of interventional methods of digital films and pamphlet on students' knowledge about hookah smoking. 


\section{Material and Methods}

\subsection{Study design and eligibility criteria}

The study was a semi-empirical study that was conducted on 200 male students aged 15-18 years old from 4 high schools of Zahedan (South-East of Iran) in 2014. The study was conducted before and after the interventions with two interventional groups with digital films and pamphlet procedures that were aimed to assess the impact of digital media designed to reduce water pipe consumption. The inclusion criteria were high school students studying in Zahedan district, willingness to participate in the study, not being absent during the study period, and the parents' satisfaction.

\subsection{Sampling}

The study samples were high school students who were studying in 4 schools that were randomly divided into two groups of interventions (intervention by digital films and pamphlets procedures). According to the formula, the confidence level of $Z=95 \%=1.77$ and the power of $76 \%$ calculated. In addition, the mean and standard deviation in the two groups were considered, based on the previous studies. According to the formula, $\mathrm{S}_{1}=0.88 \%$ and $\mathrm{S}_{2}=1.01$, the sample size of 88 students was achieved in each group and with considering an excess number of study sample due to withdrawal (missing), about 100 students were chosen to participate in each study group. Five high schools were randomly selected from the list of all high schools. One high school was selected to determine the study reliability and four high schools were selected for two interventional groups (two high schools in each group). According to the class list (grades one, two, and three) and the study field, 50 students were randomly selected from each high school. One hundred students were trained by using digital films and 100 students were trained by using pamphlet education. In total, 200 students were selected to participate in the study and the measurement was performed before and two months after the intervention.

\subsection{Instrument}

The data collected through a researcher-made questionnaire with 53-items consisted of five sections of demographic, knowledge, attitude, behavior and self-efficacy questions in before and after the interventions. The demographic section questions including (age, major of study, average study score in previous year, the father's and mother's education, father's and mother's occupation). The students answered to knowledge, self-efficacy, and practice section questions by Yes, No, and I don't know responses and the students' attitudes were measured according to the 5-likert scale, i.e. completely agree, agree, uncertain, disagree, and completely disagree. The questionnaire was based on a standard questionnaire of Global Youth Tobacco Survey (GYTS) by the World Health Organization. The questionnaire validity and reliability were confirmed. The questionnaire validity was checked by fifteen experts in health promotion fields and the content validity were evaluated by two indexes of CVR and CVI that were $0.62 \%$ and $0.80 \%$, respectively. To determine the questionnaire reliability, test-retest and the Cronbach's alpha coefficient was done. In the test-retest method, within 10 days, the questionnaire filled by 20 students whom were similar to the study population. Then the Pearson-product moment correlation coefficient calculated $(p=0.777)$ and Cronbach's alpha was 0.87 .

\subsection{Pre-test}

At the entrance to each of the high schools and before distributing the questionnaires, the study goals and objectives were explained. The questionnaires were distributed and explained on how to complete them. The completed anonymous questionnaires were remarked by a code by the students themselves to ensure them that data was collected confidentially.

\subsection{Development and implementation of training program}

According to the results obtained in the pre-test (pilot study) and the needs assessment that was done based on the objectives of the study, the training programs prepared for two types of digital film and pamphlets procedures and implemented for two groups. The digital media training was an eight minute vocative film that was illustrated for students and then one copy of the $\mathrm{CD}$ was given to them or the file was shared to their cell phones by Bluetooth. The designed pamphlet was given to another interventional group. It should be noted that all materials (educational content) that were used in digital film corresponded accurately with the designed pamphlet. Also, the educational content provided in the two media types were based on the results obtained from the different parts of the pre-test (pilot) study. 


\subsection{Evaluation of training program}

To evaluate the educational programs, the study groups were assessed in two different time periods, before and three months after the interventional training, through a questionnaire.

\subsection{Data analysis}

Finally, the data analysis was conducted using SPSS software to assess the impact of digital films and pamphlets. The descriptive statistics (such as means, standard deviation, and frequency tables) and paired t-test were used to compare the means differences before and after the intervention within groups, independent sample t-test for comparing the two groups of the study, and Chi-Squire (for demographic variables) were used. Parametric tests (Pearson correlation coefficient) and non-parametric tests (Spearman correlation and Kruskal-Wallis) were used to assess the correlation between the variables. To analyze the data, before and after the interventions, Mann-Whitney U-test and Chi square tests were performed using SPSS version 18 (SPSS Inc., Chicago, Illinois, USA). The significance level was set at $\mathrm{p} \leq 0.05$.

\subsection{Ethics of research}

The study participation was voluntary and the students participated in the study with consent and were assured that their names and their schools name would not be mentioned. The study objectives were explained to students and their parents, teachers, educational authorities, and schools' administrators. During the educational programs, the authors tried to avoid any interruption on the student's classes. Difficulty in obtaining permission from the educational authorities was one of the study limitations and another was that entry into the high schools for administrating the educational programs was with difficulty.

\section{Results}

In the study, 200 students participated in two groups. The mean age of participants was 15.66 and 15.28 , in the intervention by film and pamphlets groups, respectively. Moreover, most of participants were in human science courses. The participants' demographic variables are shown in Table 1.

Table 1. Demographic variables of students in intervention and control groups in the high schools in Zahedan

\begin{tabular}{|c|c|c|c|}
\hline Variables & Dimensions & $\begin{array}{l}\text { Intervention by } \\
\text { film; } \mathrm{n}(\%)\end{array}$ & $\begin{array}{l}\text { Intervention by } \\
\text { pamphlet; } \mathrm{n}(\%)\end{array}$ \\
\hline \multirow[t]{5}{*}{ Age (Year) } & 14 & $9(9)$ & $27(27)$ \\
\hline & 15 & $37(37)$ & $39(39)$ \\
\hline & 16 & $36(36)$ & $17(17)$ \\
\hline & 17 & $15(15)$ & $13(13)$ \\
\hline & 18 & $3(3)$ & $4(4)$ \\
\hline \multirow[t]{5}{*}{ Course } & Mathematics & $21(21)$ & $16(16)$ \\
\hline & Experimental sciences & $31(31)$ & $28(28)$ \\
\hline & Humanities & $27(27)$ & $25(25)$ \\
\hline & Work-based & $7(7)$ & $17(17)$ \\
\hline & Vocational & $14(14)$ & $14(14)$ \\
\hline \multirow[t]{3}{*}{ Fathers' education (level) } & Elementary & $30(30)$ & $57(57)$ \\
\hline & Pre-high school diploma & $36(36)$ & $26(26)$ \\
\hline & High school diploma & $34(34)$ & $17(17)$ \\
\hline \multirow[t]{3}{*}{ Mothers' education (level) } & Elementary & $61(61)$ & $80(80)$ \\
\hline & Pre-high school diploma & $22(22)$ & $12(12)$ \\
\hline & High school diploma & $17(17)$ & $8(8)$ \\
\hline \multirow[t]{5}{*}{ Fathers' job } & Worker & $28(28)$ & $27(27)$ \\
\hline & Staff & $9(9)$ & $8(8)$ \\
\hline & Self-employment & $47(47)$ & $52(52)$ \\
\hline & Educational staff & $7(7)$ & $5(5)$ \\
\hline & Unemployed & $9(9)$ & $8(8)$ \\
\hline \multirow[t]{3}{*}{ Mothers' job } & Worker/Staff & $6(6)$ & $9(9)$ \\
\hline & Educational staff & $5(5)$ & $5(5)$ \\
\hline & Housewife & $89(89)$ & $86(86)$ \\
\hline
\end{tabular}


The results of the study showed that knowledge, attitude, efficacy and behavior of the students about hookah use were increased after implementation both by pamphlet and film; however, this was increased more in the film group rather than the pamphlet. Moreover, as shown in Table 2, there are significant associations between all dependent variables and intervention in the film educational group $(\mathrm{p}<0.05)$. It shows that film educational intervention was more effective than the pamphlet method. According to Table 3, the age of the students had a positive association with attitude; Moreover, efficacy of students had association with the grade point average of the previous year and also their father's job $(\mathrm{p}<0.05)$. The relation between other demographic variables and dependent variables are shown in Table 3.

Table 2. Mean score of knowledge, attitude, Efficacy and behavior of the students in the film and pamphlet educational groups in Zahedan.

\begin{tabular}{|l|l|l|l|l|l|}
\hline \multirow{2}{*}{ Depended variables } & Pamphlet $($ Mean \pm SD) & Film $($ Mean \pm SD) & \multirow{2}{*}{-value } \\
\cline { 2 - 6 } & Before intervention & After intervention & Beforeintervention & After intervention & \\
\hline knowledge & $29.48 \pm 8.28$ & $30.20 \pm 8.25$ & $35.32 \pm 4.95$ & $38.86 \pm 4.08$ & 0.03 \\
\hline Attitude & $42.93 \pm 12.47$ & $43.25 \pm 12.41$ & $53.75 \pm 9.47$ & $59.54 \pm 7.81$ & 0.001 \\
\hline Efficacy & $15.68 \pm 4.90$ & $15.75 \pm 4.85$ & $19.20 \pm 4.00$ & $20.75 \pm 3.04$ & 0.001 \\
\hline Behavior & $20.76 \pm 4.56$ & $21.0 \pm 4.55$ & $23.74 \pm 4.07$ & $26.07 \pm 2.46$ & 0.001 \\
\hline
\end{tabular}

Table 3. Relationship between knowledge, attitude, efficacy and behavior, and demographic variables in the students in the film and pamphlet educational groups in Zahedan.

\begin{tabular}{|l|l|l|l|l|l|l|l|l|}
\hline \multirow{2}{*}{ Variables } & \multicolumn{2}{l}{ Knowledge } & \multicolumn{2}{l|}{ Attitude } & \multicolumn{2}{l|}{ Efficacy } & \multicolumn{2}{l|}{ Behaviour } \\
\cline { 2 - 10 } & $\mathrm{R}$ & $\mathrm{p}$-value & $\mathrm{R}$ & $\mathrm{p}$-value & $\mathrm{R}$ & $\mathrm{p}$-value & $\mathrm{R}$ & $\mathrm{p}$-value \\
\hline Age & 0.140 & 0.083 & 0.196 & 0.025 & 0.137 & 0.087 & 0.039 & 0.350 \\
\hline Average & 0.149 & 0.069 & 0.043 & 0.336 & 0.191 & 0.028 & 0.120 & 0.118 \\
\hline Father education & 0.513 & 0.976 & 1.019 & 0.450 & 2.159 & 0.011 & 1.237 & 0.079 \\
\hline Mother education & 0.513 & 0.976 & 1.389 & 0.082 & 1.471 & 0.113 & 1.238 & 0.051 \\
\hline Father's job & 0.735 & 0.820 & 1.102 & 0.331 & 1.830 & 0.408 & 1.004 & 0.156 \\
\hline Mother's job & 0.651 & 0.734 & 1.062 & 0.211 & 1.750 & 0.321 & 1.233 & 0.076 \\
\hline
\end{tabular}

\section{Discussion}

The study showed that knowledge, attitude, efficacy and behavior of the students who were educated by film were higher than those who were educated by pamphlet. This shows that new technology such as film could have a more impressive effect than older methods. Since film applicability in young people such as students is more than others, there should be more attention from health education experts and school administrators. The health education program for students in high school age is very important, as Heydarabadi indicated that $48 \%$ of students, who used drugs, started it for the first time when they were 18 years old or younger (18). Moreover, a study showed that social networks represent valuable and untapped potential resources for communicating with younger people about risks and harm reduction related to emerging nicotine/tobacco products (19). Social media usage among the child and adolescent population is at an all-time high across the globe (20). It could be an important opportunity to bring awareness of the harmfulness of hookah usage to young people. Social media provides an opportunity for "usergenerated" disease control and prevention interventions that employ users' behavior, knowledge, and existing social networks for the creation and dissemination of interventions (21). Rao, in a study, showed that media tolls could increase student knowledge more than the traditional method of using print media such as folders, leaflets or charts in the health education program (22). However, media could have a negative role in student life, and Primack indicated that websites may play a role in enhancing or propagating misinformation related to hookah tobacco smoking. He emphasized that health education and policy measures may be valuable in countering this misinformation (23). Therefore, as discussed above, it is necessary for health managers to pay more attention to media tools for use in health educational programs for students. According to the study results, there was positive association between age and the students' attitude. It showed that students' negative attitude about hookah use increased with their age. In confirmation of this study, Enofe indicated that younger students (under 20 years) were at increased risk of alternative tobacco product use (24). Also, some studies showed that students in the age range of 20-25 had higher attitudes to hookah use than the 18-20 age group $(25,26)$. In this regard Lee found that lower age is a risk factor in students' use of the hookah (27). In addition, other studies emphasized that more younger students than adolescents had attitudes towards tobacco use such as hookahs (28-30). Moreover, a study by Engels et al showed that in adolescent smokers, self-efficacy and attitude towards smoking were predictive of smoking status 
three years later (25). Attention to students' attitude towards hookah use could be helpful for parents in its prevention. Moreover, a study showed that most students (58.3\%) had moderate positive attitudes towards drugs (31). The positive attitude of students is a risk factor in the community, and more attention by parents, school and health system administrators is needed. Based on what researchers suggest, knowledge alone is not sufficient to prevent smoking among adolescents (8), since many misinterpret the risks involved. Considering the abovementioned findings, planning and implementation of educational programs seem necessary in order to correct the attitude of students and promotion of knowledge toward smoking. The study indicated that students who had higher grade point averages (GPA), had more efficacy for non-consumption of hookah. Maybe it showed that those who spent more time studying and have better grade point averages have no tendency to use a hookah. A study showed that hookah use is higher in students with lower GPA (32). Another study confirms the finding of the study (33). Therefore, parents and school administrators should pay more attention to students' study time and trend of students' GPA in the school. According to the results, higher education of the father lead to higher efficacy in the students, to prevention of drugs use such as hookah. It may indicate that the father who had a higher education had appropriate knowledge about hookah use and gave greater attention to education and training of their children. In confirmation of this study, Honarmand indicated that hookah use decreased the higher the father's education (32). On the other hand, Ziaodini found that use of hookah, tobacco and marijuana is higher in students whose fathers had lower education (34). However, Heshmati found that there was no association between factors enabling the use of hookah and father's education (35). Therefore, fathers should pay attention to this issue, particularly those who have under diploma education, and whose children may have tendency to use the hookah, and should prevent it by increasing their awareness in this matter. (32). Although there was no significant association between a mother's education and hookah use, mothers who had a higher education could change their children's behavior to a correct healthy manner. Honarmand found that a mother's education is a predictive for tobacco use in students, as students whose mothers had a higher education, use less than mothers who had a lower education Ziaodini stated that a mother's lower education could lead to children's use of tobacco, hookah, alcohol and cigarettes (34). Limitations of the study: Organization of Education had low cooperation by researchers and this was a limitation that they could overcome by higher coordination of Health Centers and the mentioned organization.

\section{Conclusions}

Educational digital media is more efficient than the pamphlet in the reduction of hookah use among the students, and that the media may be applied to prevent students from hookah use. The results of the study could be helpful for school administrators and health system managers prevention of tobacco use. Moreover, parents could have a more preventative role in keeping their children from tobacco and hookah by increasing their education. It is recommended that future studies are done in the consumption of tobacco.

\section{Acknowledgments:}

The present study is extracted from MSc thesis by M. Shojaeifar, which is supported by Tarbiat Modares University.

\section{Conflict of Interest:}

There is no conflict of interest to be declared.

Authors' contributions:

All authors contributed to this project and article equally. All authors read and approved the final manuscript.

\section{References:}

1) Klein JD. Hookahs and waterpipes: cultural tradition or addictive trap? Journal of Adolescent Health. 2008; 42(5): 434-5. doi: 10.1016/j.jadohealth.2008.02.006. PMID: 18407037.

2) Khabour OF, Alzoubi KH, Eissenberg T, Mehrotra P, Azab M, Carroll MV, et al. Waterpipe tobacco and cigarette smoking among university students in Jordan. Int J Tuberc Lung Dis. 2012; 16(7): 986-92. doi: 10.5588/ijtld.11.0764. PMID: 22525279, PMCID: PMC3570564.

3) Chan WC, Leatherdale ST, Burkhalter R, Ahmed R. Bidi and hookah use among Canadian youth: an examination of data from the 2006 Canadian Youth Smoking Survey. Journal of Adolescent Health. 2011; 49(1): 102-4. doi: 10.1016/j.jadohealth.2010.11.250. PMID: 21700168.

4) Sabahy AR, Divsalar K, Bahreinifar S, Marzban M, Nakhaee N. Waterpipe tobacco use among Iranian university students: correlates and perceived reasons for use. Int J Tuberc Lung Dis. 2011; 15(6): 844-7. doi: 10.5588/ijtld.10.0744. PMID: 21575309. 
5) Salloum RG, Thrasher JF, Kates FR, Maziak W. Water pipe tobacco smoking in the United States: findings from the National Adult Tobacco Survey. Prev Med. 2015; 71: 88-93. doi: 10.1016/j.ypmed.2014.12.012. PMID: 25535678, PMCID: PMC4423406.

6) Eissenberg T, Ward KD, Smith-Simone S, Maziak W. Waterpipe tobacco smoking on a US College campus: prevalence and correlates. J Adolesc Health. 2008; 42(5): 526-9. doi: 10.1016/j.jadohealth.2007.10.004. PMID: 18407049, PMCID: PMC2362063.

7) Jawad M, Nakkash RT, Mahfoud Z, Bteddini D, Haddad P, Afifi RA. Parental smoking and exposure to environmental tobacco smoke are associated with waterpipe smoking among youth: results from a national survey in Lebanon. Public health. 2015; 129(4): 370-6. doi: 10.1016/j.puhe.2015.01.011. PMID: 25749674.

8) Karimy M, Niknami S, Heidarnia AR, Hajizadeh E, Shamsi M. Refusal self efficacy, self esteem, smoking refusal skills and water pipe (Hookah) smoking among iranian male adolescents. Asian Pac J Cancer Prev. 2013; 14(12): 7283-8. doi: 10.7314/APJCP.2013.14.12.7283. PMID: 24460289.

9) Bakhshani NM, Dahmardei M, Shahraki Sanavi F, Hosseinbor M, Ansari Moghaddam A. Substance abuse among high school students in Zahedan. Health Scope. 2014; 3(1): e14805. doi: 10.17795/jhealthscope14805.

10) McKelvey K, Attonito J, Madhivanan P, Jaber R, Yi Q, Mzayek F, et al. Determinants of waterpipe smoking initiation among school children in Irbid, Jordan: a 4-year longitudinal analysis. Drug Alcohol Depend. 2014; 142: 307-13. doi: 10.1016/j.drugalcdep.2014.06.038. PMID: 25060962, PMCID: PMC4138134.

11) Primack BA, Sidani J, Agarwal AA, Shadel WG, Donny EC, Eissenberg TE. Prevalence of and associations with waterpipe tobacco smoking among US university students. Ann Behav Med. 2008; 36(1): 81-6. doi: 10.1007/s12160-008-9047-6. PMID: 18719977, PMCID: PMC3004534.

12) Gilreath TD, Leventhal A, Barrington-Trimis JL, Unger JB, Cruz TB, Berhane K, et al. Patterns of Alternative Tobacco Product Use: Emergence of Hookah and E-cigarettes as Preferred Products Amongst Youth. J Adolesc Health. 2016; 58(2): 181-5. doi: 10.1016/j.jadohealth.2015.10.001. PMID: 26598059, PMCID: PMC4963235.

13) Primack BA, Fertman CI, Rice KR, Adachi-Mejia AM, Fine MJ. Waterpipe and cigarette smoking among college athletes in the United States. J Adolesc Health. 2010; 46(1): 45-51. doi: 10.1016/j.jadohealth.2009.05.004. PMID: 20123257, PMCID: PMC3001225.

14) Noonan D, Kulbok P, Yan G. Intention to smoke tobacco using a waterpipe among students in a southeastern US college. Public Health Nursing. 2011; 28(6): 494-502. doi: 10.1111/j.15251446.2011.00945.x. PMID: 22092459, PMCID: PMC3319667.

15) Reveles CC, Segri NJ, Botelho C. Factors associated with hookah use initiation among adolescents. J Pediatr (Rio J). 2013; 89(6): 583-7. doi: 10.1016/j.jped.2013.08.001. PMID: 24035875.

16) King BA, Tynan MA, Dube SR, Arrazola R. Flavored-little-cigar and flavored-cigarette use among US middle and high school students. J Adolesc Health. 2014; 54(1): 40-6. doi: 10.1016/j.jadohealth.2013.07.033. PMID: 24161587, PMCID: PMC4572463.

17) Hampson SE, Andrews JA, Severson HH, Barckley M. Prospective Predictors of Novel Tobacco and Nicotine Product Use in Emerging Adulthood. J Adolesc Health. 2015; 57(2): 186-91. doi: 10.1016/j.jadohealth.2015.04.015. PMID: 26206439, PMCID: PMC4514910.

18) Babaei Heydarabadi A, Ramezankhani A, Barekati H, Vejdani M, Shariatinejad K, Panahi R, et al. Prevalence of substance abuse among dormitory students of Shahid Beheshti University of Medical Sciences, Tehran, Iran. Int J High Risk Behav Addict. 2015; 4(2): e22350. doi: 10.5812/ijhrba.22350v2. PMID: 26405679, PMCID: PMC4579756.

19) Link AR, Cawkwell PB, Shelley DR, Sherman SE. An Exploration of Online Behaviors and Social Media Use Among Hookah and Electronic-Cigarette Users. Addict Behav Rep. 2015; 2: 37-40. doi: 10.1016/j.abrep.2015.05.006. PMID: 26167519, PMCID: PMC4496793.

20) Hur J, Gupta M. Growing up in the web of social networking: Adolescent development and social media. Adolescent Psychiatry. 2013; 3(3): 233-44. doi: 10.2174/2210676611303030004.

21) Cavallo DN, Chou WY, McQueen A, Ramirez A, Riley WT. Cancer prevention and control interventions using social media: User-generated approaches. Cancer Epidemiol Biomarkers Prev. 2014; 23(9): $1953-6$. doi: 10.1158/1055-9965.EPI-14-0593. PMID: 25103820, PMCID: PMC4154981.

22) Rao DR, Vijayapushpam T, Subba Rao GM, Antony GM, Sarma KV. Dietary habits and effect of two different educational tools on nutrition knowledge of school going adolescent girls in Hyderabad, India. Eur J Clin Nutr. 2007; 61(9): 1081-5. doi: 10.1038/sj.ejcn.1602622. PMID: 17299495. 
23) Primack BA, Rice KR, Shensa A, Carroll MV, DePenna EJ, Nakkash R, et al. US hookah tobacco smoking establishments advertised on the internet. Am J Prev Med. 2012; 42(2): 150-6. doi: 10.1016/j.amepre.2011.10.013. PMID: 22261211, PMCID: PMC3391575.

24) Enofe N, Berg CJ, Nehl EJ. Alternative tobacco use among college students: who is at highest risk? Am J Health Behav. 2014; 38(2): 180-9. doi: 10.5993/AJHB.38.2.3. PMID: 24629547.

25) Engels RC, Hale WW, Noom M, Vries Hd. Self-efficacy and emotional adjustment as precursors of smoking in early adolescence. Substance Use \& Misuse. 2005; 40(12): 1883-93. doi: 10.1080/10826080500259612. PMID: 24629547, PMCID: PMC4043211.

26) Mansour MA, Youssef HA, Al-Mawajdeh NA, Ayasreh IR. Awareness, Attitude and Practice of Smoking among Medical Sciences\& Non-Medical Sciences Students at Taif University: Comparative Study. IJSR. 2015; 438(1): 255-64.

27) Lee YO, Bahreinifar S, Ling PM. Understanding tobacco-related attitudes among college and noncollege young adult hookah and cigarette users. J Am Coll Health. 2014; 62(1): 10-8. doi: 10.1080/07448481.2013.842171. PMID: 24313692, PMCID: PMC3920485.

28) Rezk-Hanna M, Macabasco-O'Connell A, Woo M. Hookah smoking among young adults in southern California. Nurs Res. 2014; 63(4): 300-6. doi: 10.1097/NNR.0000000000000038. PMID: 24977727.

29) Holtzman AL, Babinski D, Merlo LJ. Knowledge and attitudes toward hookah usage among university students. J Am Coll Health. 2013; 61(6): 362-70. doi: 10.1080/07448481.2013.818000. PMID: 23930750.

30) Smith-Simone S, Maziak W, Ward KD, Eissenberg T. Waterpipe tobacco smoking: knowledge, attitudes, beliefs, and behavior in two US samples. Nicotine Tob Res. 2008; 10(2): 393-8. doi: 10.1080/14622200701825023. PMID: 18236304, PMCID: PMC3215239.

31) Heydarabadi AB, Ramezankhani A, Barekati H, Tavassoli E, Vejdani M, Kashfi SH. Knowledge and attitude of dormitory students of Shahid Beheshti University of medical sciences about substance abuse in 2013. Journal of Paramedical Sciences. 2014; 5(3).

32) Honarmand M, Farhadmollashahi L, Bekyghasemi M. Use of smokeless tobacco among male students of Zahedan universities in Iran: a cross sectional study. Asian Pac J Cancer Prev. 2013; 14(11): 6385-8. doi: 10.7314/APJCP.2013.14.11.6385. PMID: 24377537.

33) Valliani A, Ahmed B, Nanji K, Valliani S, Zulfiqar B, Fakih M, et al. Use of Smoke-less Tobacco Amongst the Staff of Tertiary Care Hospitals in the Largest City of Pakistan. Asian Pac J Cancer Prev. 2012; 13(5): 2315-7. doi: 10.7314/APJCP.2012.13.5.2315. PMID: 22901213.

34) Ziaaddini H, Sharifi A, Nakhaee N, Ziaaddini A. The prevalence of at least one-time substance abuse among kerman pre-university male students. Addiction \& health. 2010; 2(3-4): 103. PMID: 24494108.

35) Heshmati H. Enabling factors and associated factors in relation to smoking and hookah in the student dormitories of the University of Medical Sciences in 2012. Proceedings of the First National Conference on applied research in public health and sustainable development. 2013; 1(1). 